\title{
Hyaluronidase facilitated subcutaneous immunoglobulin in primary immunodeficiency
}

This article was published in the following Dove Press journal:

ImmunoTargets and Therapy

18 September 2013

Number of times this article has been viewed

\section{Stephen Jolles}

Department of Immunology, University Hospital of Wales, Cardiff, UK
Correspondence: Stephen Jolles Department of Immunology, University Hospital of Wales, Heath Park, Cardiff, CFI4 4XW, UK

Tel +4429207458I4

Fax +442920748383

Email jollessr@cardiff.ac.uk

\begin{abstract}
Immunoglobulin (Ig)-replacement therapy represents the mainstay of treatment for patients with primary antibody deficiency and is administered either intravenously (IVIg) or subcutaneously (SCIg). While hyaluronidase has been used in clinical practice for over 50 years, the development of a high-purity recombinant form of this enzyme (recombinant human hyaluronidase $\mathrm{PH} 20$ ) has recently enabled the study of repeated and more prolonged use of hyaluronidase in facilitating the delivery of SC medicines. It has been used in a wide range of clinical settings to give antibiotics, local anesthetics, insulin, morphine, fluid replacement, and larger molecules, such as antibodies. Hyaluronidase has been used to help overcome the limitations on the maximum volume that can be delivered into the SC space by enabling dispersion of SCIg and its absorption into lymphatics. The rate of facilitated SCIg (fSCIg) infusion is equivalent to that of IVIg, and the volume administered at a single site can be greater than $700 \mathrm{~mL}$, a huge increase over conventional SCIg, at 20-40 mL. The use of fSCIg avoids the higher incidence of systemic side effects of IVIg, and it has higher bioavailability than SCIg. Data on the long-term safety of this approach are currently lacking, as fSCIg has only recently become available. fSCIg may help several areas of patient management in primary antibody deficiency, and the extent to which it may be used in future will depend on long-term safety data and cost-benefit analysis.
\end{abstract}

Keywords: enzyme facilitated IgG infusion, recombinant human hyaluronidase PH20, subcutaneous immunoglobulin, intravenous immunoglobulin, primary immunodeficiency disease

\section{Immunoglobulin in primary antibody deficiency}

Immunoglobulin (Ig) replacement is the established mainstay of treatment for patients with a primary failure to produce either sufficient quantity or quality of antibodies. It was first given subcutaneously (SCIg) by Bruton in $1952^{1}$ in an 8-year-old boy with agammaglobulinemia, and following the original report, intramuscular Ig (IMIg) was widely used for more than 30 years. IM administration is painful and associated with systemic reactions in a high proportion of patients. ${ }^{2}$ In addition, it is not possible to achieve therapeutic Ig levels within the normal range, given the constraints on volume of injection, product concentration, and patient acceptability using regimens of $0.1 \mathrm{~g} / \mathrm{kg}$ every 3 weeks, which were customary at that time. ${ }^{3}$

The intravenous route of administration for Ig (IVIg) became more frequently used with the development of improved Ig-manufacturing processes from plasma in the 1980s. IVIg largely replaced IMIg, with fewer side effects and the ability to deliver sufficient Ig for IgG-trough levels to be within the normal range for the first time. The use of higher doses than had previously been possible $(0.4 \mathrm{~g} / \mathrm{kg} / \mathrm{month})$ achieved trough 
levels of at least $5 \mathrm{~g} / \mathrm{L}$ and greater reduction of sinopulmonary infections. ${ }^{4}$ While the tolerability of IVIg is excellent, some patients experience "rate-related" side effects, which include flu-like symptoms, muscle ache, low-back pain, headache, and tiredness. More severe side effects, such as anaphylaxis, aseptic meningitis, thrombosis, and renal failure, rarely occur, though these are more frequent when much higher doses of $\operatorname{Ig}(2 \mathrm{~g} / \mathrm{kg})$ are used for immunomodulation rather than replacement. Over the past few years, there has been a degree of convergence of the doses used, as replacement doses have increased, and immunomodulatory doses have for some conditions decreased.

Having been the first route of administration used by Bruton in 1952, SCIg underwent a renaissance in the 1990s with the development of more concentrated Ig preparations, the use of infusion pumps, and the recognition of the safety of higher infusion rates. ${ }^{5}$ This route of administration has advantages, in that systemic adverse events are reduced and it avoids the need for venous access, thus making training for home therapy a quicker and much more straightforward process. Patients are empowered to take greater control of the treatment of their condition, and fewer visits to hospital are needed. Children in particular benefit from SCIg when venous access is difficult, but at the cost of more frequent infusions, given the limited volume that can be administered at a single site. Studies show improved quality of life of primary antibody deficiency patients when they receive SCIg home therapy. ${ }^{6}$

Technical advances in the manufacture and stabilization of Ig have enabled higher concentrations of $16 \%$ and $20 \%$ SCIg to be achieved, ${ }^{7}$ thus reducing the volume and time required for infusion. This has enabled some patients to choose fortnightly rather than weekly SCIg infusion regimens, further improving convenience. For other patients for whom ease of administration without infusion pumps is important, "rapid push" of smaller volumes given more regularly using only a syringe and butterfly needle has proved an attractive option. ${ }^{8}$

When comparing different routes of administration and dosing regimens, it is important to understand the fate of the injected Ig molecules. Ig has the longest half-life of any plasma protein, at around 21-28 days, and this is due to its salvage and recycling by the neonatal Fc receptor $(\mathrm{FcRn}) .{ }^{9}$ This is a saturable system that has catabolic implications if high peak-Ig levels are achieved using IVIg that are greater than the capacity of FcRn to recycle. SCIg enters the vascular space indirectly via lymphatics rather than capillaries due to its high molecular weight (150 kDa).
This means that the flow of SCIg into the vascular space is much more gradual and the high plasma-peak levels of IVIg are not attained.

\section{Immunoglobulin dose}

The dose of $\operatorname{Ig}(\mathrm{g} / \mathrm{kg} /$ month) and the trough level of $\operatorname{IgG}$ being used to treat and monitor replacement adequacy in primary antibody-deficient patients has tended to increase from the doses used in the studies of the late 1980s. ${ }^{4}$ This trend has been supported by more recent analyses of dose and clinical outcome in patients receiving IVIg and SCIg. ${ }^{10,11}$ This has resulted in a convergence of doses used for antibody replacement and the traditionally much higher doses used for immunomodulation. The use of higher replacement doses in some patients receiving SCIg results in more infusion sites per infusion, and this may become burdensome for patients. In practice, if it is possible to keep to two sites per week, this is less time-consuming than infusing on more than one day per week or using more than two sites. In the US, the FDA requirement to maintain the patient's Ig exposure to the area under the curve (AUC) of the IVIg dose has resulted in the inclusion of adjustment factors for a switch from IVIg to SCIg ranging from 1.37 to 1.53 times the previous IV dose. ${ }^{12} \mathrm{In}$ theory, this has meant that higher doses and volumes would be needed for conventional SCIg, which has a bioavailability of $67 \%$, compared to that of fSCIg, at $92 \%$. There is an ongoing debate regarding the need for these adjustments. Individualized dosing based on the clinical response and infection frequency will remain key in the management of this heterogeneous group of patients with primary antibody deficiency. This has been eloquently discussed by Bonagura et al, who describe different biological Ig levels required to keep patients infection-free. ${ }^{13}$

\section{Hyaluronidase biology}

The observation that rabbit testes contained a factor that enhanced spreading in the dermis was made as early as 1928. Writing in Nature in 1939, Chaik and Duthie suggested, “... it seemed to us likely that it was an enzyme acting on some substrate in the skin, causing the removal of a barrier to the rapid diffusion of intradermally injected fluids." 14

The enzyme activity was subsequently defined as a hyaluronidase based on its ability to digest hyaluronan in vitro. ${ }^{15}$ It is found not only in testes extracts but also in other settings, such as snake venom, bee venom, leeches, and certain bacteria. Mammalian hyaluronidases can be further divided into neutral-active (testes) and acid-active (liver) enzymes. These enzymes are endo- $\beta$ - $N$-acetylhexosaminidases, which 
after digestion of hyaluronan leave tetrasaccharides and hexasaccharides as the main end products. ${ }^{16}$ Bovine and ovine testes extracts were subsequently developed for therapeutic use by a number of pharmaceutical companies, and while these extracts are known to contain other contaminants, they remain in clinical use today.

Six human hyaluronidase-like genes have been identified: three genes (HYAL1, HYAL2, and HYAL3) are clustered on chromosome 3p21.3, and another two genes (HYAL4 and PH-20/SPAM1) and one expressed pseudogene (HYALP1) are similarly clustered on chromosome $7 \mathrm{q} 31.3 .{ }^{17}$ It appears likely that these have resulted from gene duplication and block duplication. Hyal-1 is the only hyaluronidase in mammalian plasma and urine, and is also found at high levels in major organs, such as liver, kidney, spleen, and heart.

Most mammalian ova are coated in a layer of granulosa cells entwined with a layer of extracellular matrix (ECM), which is high in hyaluronan. Hyaluronidase released by the sperm acrosome enables fertilization; however, gene-targeting studies show that $\mathrm{PH}-20$ is not essential for fertilization. A very rare deficiency of HYAL1 (mucopolysaccharidosis IX) has been described, with a clinical phenotype of joint pain and swelling. ${ }^{18}$ A recent study identified a $16.1 \mathrm{~Kb}$ duplication upstream of the hyaluronan synthase 2 (HAS2) gene in shar-pei dogs, which have a phenotype with loose folds of thickened skin. ${ }^{19}$ The shar-pei breed also has a high incidence of shar-pei fever, which is similar to periodic fever syndromes in humans and is associated with amyloidosis. The copy number of the $16.1 \mathrm{~Kb}$ duplication correlates with $H A S 2$ expression and disease, and it is postulated that in familial shar-pei fever, the hyaluronanosis leads to an increase in "danger signals" and the development of sterile fevers. Lower-molecular-weight fragments of hyaluronan potentially acting through cellular receptors such as CD44 and TLR4 may modulate the immune response towards activation of the innate immune system. ${ }^{20-22}$

The development of a recombinant human hyaluronidase followed the discovery of homology between bee venom hyaluronidase and the mammalian sperm-surface protein $\mathrm{PH}-20$ and the hyaluronidase activity of $\mathrm{PH}-20{ }^{23-25}$

Recombinant human PH-20 (rHuPH20) has been produced in bulk and purified to homogeneity with a 50- to 100-fold greater specific activity than commercially available testis extracts of animal origin. ${ }^{16}$ RHuPH20 $\left(\right.$ Hylenex $^{\circledR}$ ) has indications for use as an adjuvant to enhance the absorption and dispersion of other injected drugs, for hypodermoclysis (the SC administration of a solution), as an adjunct to SC urography and for improving the resorption of radiopaque drugs.
Bovine and ovine hyaluronidase preparations have been used for some time for hypodermoclysis, periocular blocks, drug extravasation, and absorption of radiopaque agents. RHuPH20 has been used to facilitate fluid delivery ${ }^{26,27}$ as well as insulin ${ }^{28}$ and ceftriaxone. ${ }^{29}$

\section{Skin structure}

Following an SC injection, a drug must pass through the skin extracellular matrix (ECM) in order to access either capillaries or the lymphatics to enter the vascular space. For small molecules, entry is via the capillaries; however, larger molecules such as antibodies pass into the lymphatics through their fenestrated endothelium ${ }^{30}$ (Figure 1).

The ECM contains the structural macromolecules collagen and elastin, which support cellular, vascular, and lymphatic components, and all of these are embedded in a viscoelastic gel made from glycosaminoglycans and proteoglycans. It is the ability of the complex polysaccharide structure of glycosaminoglycans to retain water that forms the gel-like substance, and this acts to impede the flow of fluids through the ECM. All of the glycosaminoglycans except for hyaluronan are covalently bound to core proteins and are then termed proteoglycans. Hyaluronan has a very rapid turnover,

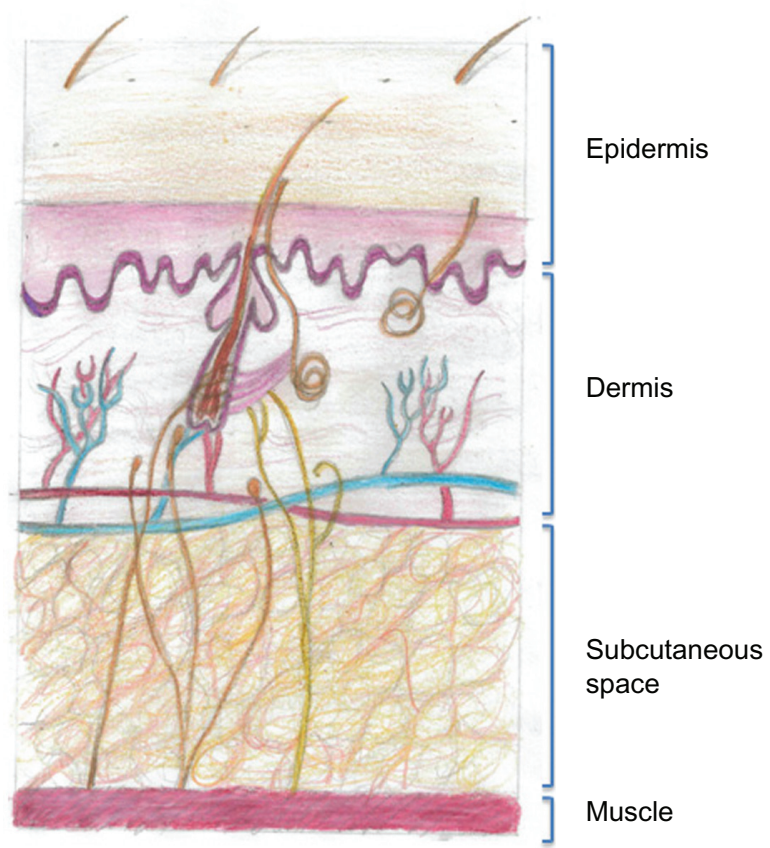

Figure I Drawing of the structure of the anatomy of human skin. The subcutaneous space contains cells and extracellular matrix, within which are such structural components such as collagen and elastin fibers that support blood and lymphatic vessels. All of the cells and vessels and the structural-scaffold proteins collagen and elastin are embedded in a gel-like substance made up of glycosaminoglycans and proteoglycans. When a subcutaneous injection is given, small molecules are absorbed through the capillary endothelium; however larger molecules, such as antibodies, are excluded from capillaries and enter through the larger pores of the fenestrated lymphatic endothelium. 
with a half-life of 2 days, ${ }^{31}$ and its physiological functions comprise lubrication (particularly in the synovium), water homeostasis, maintenance of tissue architecture, macromolecular filtering, and exclusion.

It is estimated that $30 \%$ of the body's hyaluronan is turned over per day, and that the dermal barrier following administration of hyaluronidase is reconstituted within 24-48 hours. ${ }^{32}$ It is interesting to note that when hyaluronan is used in the context of cosmetic dermal fillers, it is chemically treated to cross-link the molecules in order to avoid the rapid degradation that would otherwise take place. ${ }^{33}$ The plasma half life of hyaluronan following IV injection of hyaluronidase into animals is very short, at $30-60$ seconds. ${ }^{16}$

The administration of hyaluronidase to break down hyaluronan temporarily and locally would allow increased movement of fluid through the ECM and access a much greater three-dimensional surface area of lymphatics, facilitating the absorption of large molecules, such as Ig (150 kDa).

\section{Routes of immunoglobulin administration}

The limitations on the maximum amount of Ig that can be administered at a single site have been addressed in two ways: firstly by making more concentrated SCIg preparations and secondly by increasing the volume delivered. There have been technical advances in the production of newer Igs with the development of products with $20 \%$ concentration. $^{7}$ Challenges will remain in terms of avoiding aggregation of Ig molecules at still-higher concentrations; however, it is likely that some further increases in concentration will be achieved.

In routine use, SCIg may be administered at a volume of 20-40 mL into an individual site in an adult, ${ }^{34}$ though there is much individual variation as to the volumes tolerated. In our immunodeficiency cohort in Cardiff, the highest volume used is $60 \mathrm{~mL}$ into a single site.

The delivery of much-higher volumes of $716 \mathrm{~mL}$ to an SC site using hyaluronidase $10 \%$ fSCIg has been demonstrated, ${ }^{35}$ and 16\% fSCIg home therapy has been described using ovine hyaluronidase with volumes of $130 \mathrm{~mL}$ per site. ${ }^{36}$

An alternative replacement strategy termed "rapid push" has also been used in primary immune deficiency (PID), in which the patient self-administers smaller volumes of SCIg using only a needle or butterfly and syringe, thus avoiding the need for pumps. ${ }^{8}$ The different routes are compared in Table 1 .

Table I Differences between routes of administration

\begin{tabular}{|c|c|c|c|c|c|}
\hline & $\begin{array}{l}\text { Intravenous } \\
\text { immunoglobulin } \\
\text { (IVIg) }\end{array}$ & $\begin{array}{l}\text { Subcutaneous } \\
\text { immunoglobulin } \\
\text { (SClg) }\end{array}$ & $\begin{array}{l}\text { Facilitated subcutaneous } \\
\text { immunoglobulin (fSClg) } \\
\text { with I } 0 \% \text { IVIg using } \\
75 \text { U/g rHuPH20 }\end{array}$ & $\begin{array}{l}\text { Facilitated subcutaneous } \\
\text { immunoglobulin (fSClg) } \\
\text { with } 16 \% \text { SClg using } \\
50 \text { U/g ovine hyaluronidase }\end{array}$ & Rapid push \\
\hline Venous access & Yes & No & No & No & No \\
\hline $\begin{array}{l}\text { Maximum infusion } \\
\text { rate }\end{array}$ & $300 \mathrm{~mL} /$ hour & $40 \mathrm{~mL} / \mathrm{hour}$ & $160-300 \mathrm{~mL} /$ hour & 100 mL/hour & $\mathrm{I}-2 \mathrm{~mL} / \mathrm{minute}$ \\
\hline Maximal volume & NA & 40 mL/site & Up to $716 \mathrm{~mL} / \mathrm{site}$ & $100-200 \mathrm{~mL} / \mathrm{site}$ & $20 \mathrm{~mL}$ \\
\hline Maximal dose/hour & $30 \mathrm{~g}$ & $6.4-8 \mathrm{~g} /$ site & $16-30 \mathrm{~g}$ & $16 \mathrm{~g}$ & NA \\
\hline Home therapy & Yes & Yes & Yes & Yes & Yes \\
\hline $\begin{array}{l}\text { Infusion time per } \\
\text { month (IVIg every } \\
3 \text { weeks) }\end{array}$ & 2.9 hours & $5-6$ hours & 2.7 hours & 3-4 hrs (fortnightly dosing) & $3-6 \mathrm{hrs}$ \\
\hline $\begin{array}{l}\text { Training time for } \\
\text { home }\end{array}$ & $\begin{array}{l}4-6 \text { sessions over } \\
3-6 \text { months }\end{array}$ & $\begin{array}{l}4-6 \text { sessions over } \\
1-6 \text { weeks }\end{array}$ & $\begin{array}{l}4-6 \text { sessions over } \\
2-6 \text { months }\end{array}$ & $\begin{array}{l}4-6 \text { sessions over } \\
2-6 \text { months }\end{array}$ & $\begin{array}{l}4 \text { sessions } \\
\text { over } 4 \text { days }\end{array}$ \\
\hline $\begin{array}{l}\text { Minimum required } \\
\text { hyaluronidase dose }\end{array}$ & NA & NA & $75 \mathrm{U} / \mathrm{g}$ & $50 \mathrm{U} / \mathrm{g}$ & NA \\
\hline Bioavailability & $100 \%$ & $67 \%$ & $92 \%$ & $\begin{array}{l}\text { Likely similar to } 92 \% \\
\text { (not studied) }\end{array}$ & $\begin{array}{l}\text { Likely similar } \\
\text { to } 67 \%\end{array}$ \\
\hline $\begin{array}{l}\text { Peak/trough } \\
\text { variation }\end{array}$ & Large & $\begin{array}{l}\text { Minor (slightly } \\
\text { more with } \\
\text { fortnightly dosing) }\end{array}$ & $\begin{array}{l}\text { Intermediate, dependent } \\
\text { on treatment interval }\end{array}$ & $\begin{array}{l}\text { Intermediate, dependent } \\
\text { on treatment interval }\end{array}$ & Negligible \\
\hline $\begin{array}{l}\text { High-dose } \\
\text { immunoglobulin }\end{array}$ & Yes & $\begin{array}{l}\text { Requires multiple } \\
\text { sites }\end{array}$ & Yes - not yet studied & $\begin{array}{l}\text { Yes, equivalent monthly } \\
\text { dose achieved }\end{array}$ & $\begin{array}{l}\text { No - not } \\
\text { studied }\end{array}$ \\
\hline Pump requirement & No & Yes & Yes, high volume & Yes, high volume & No \\
\hline
\end{tabular}

Notes: The values for fSClg are based on published studies, ${ }^{35,36}$ and calculations have been made assuming a 3-week interval between intravenous or recombinant human hyaluronidase ( $\mathrm{rHu}$ )-PH20 facilitated infusions of a $70 \mathrm{~kg}$ patient receiving $0.5 \mathrm{~g} / \mathrm{kg} / \mathrm{month}$. The training times reflect four to six training sessions spaced $3-4 \mathrm{weeks}$ apart for IVlg and weekly for SClg. There will however be variation between individuals and practice in different centers. Adapted by permission from BMJ Publishing Group Limited. Journal of Clinical Pathology, Knight E, Carne E, Novak B, et al., 63(9), 846-847, 2010.

Abbreviation: NA, not applicable. 


\section{Differences in immunoglobulin pharmacokinetics}

These developments will change the landscape of choice available to patients with antibody deficiency. Physicians will thus need to be aware of the significant differences in the doses of Ig that can be delivered by these routes to different compartments within the body on its journey, as well as the different pharmacokinetics using IVIg, SCIg, and fSCIg.

The best model for IVIg pharmacokinetics is a twocompartment model of distribution into the vascular and extravascular space. Plasma IgG concentrations initially decline more steeply than would be predicted by first-order kinetics, due to rapid redistribution from the vascular to the extravascular space. This is followed by a much more gradual decline in levels as the saturable FcRn binds and salvages IgG from degradation, ${ }^{9}$ as shown in Figure 2. Thus, regular IVIg infusions using a typical infusion cycle of once every 3 weeks result in a series of peaks and troughs where trough levels are used to monitor the level of replacement in antibody deficiency.

In contrast, molecules injected SC, which are larger than $15,000-20,000 \mathrm{~g} / \mathrm{mol}$, primarily reach the systemic circulation via the lymphatics. ${ }^{37} \mathrm{SCIg}$ therefore passes from the SC space via the lymphatics into the vascular compartment, and the resultant blood levels of IgG observed are much more stable without the marked peaks and troughs seen with IVIg.
Changes in plasma IgG concentration with fSCIg are in between that of IVIg and SCIg, and vary depending on the dose and interval between infusions. There are, however, key differences between fSCIg and IVIg, in that the high peakplasma concentrations attained with IVIg are lost and this may have implications for immunomodulation, where some of the effect may be related to the peak levels of IgG.

A second difference is that in using fSCIg, a much higher dose is delivered more rapidly to the lymphatic space, and the possible effects of this have not been fully studied, in part due to the difficulties in sampling the lymphatic space.

In addition, there are significant differences in bioavailability within the vascular compartment between IVIg at $100 \%$, SCIg at $67 \%$, and fSCIg at $92 \%$. The explanation for the lower bioavailability of SCIg may be that the slower absorption into the lymphatics and longer dwell time allows more local breakdown or binding, and studies from the 1970s using radiolabeled Ig in volunteers suggest approximately $15 \%$ of Ig following SCIg may be denatured. ${ }^{38}$

The difference in bioavailability may have consequences in the US, where the FDA requires doses of SCIg to match the AUC exposure for IVIg. Clinicians in both the US and Europe and the regulatory authorities in Europe, however, tend to administer the same total dose when switching from IVIg to SCIg, rather than adhering to the dose adjustments suggested of 1.37-1.53 times the IV dose for SCIg.

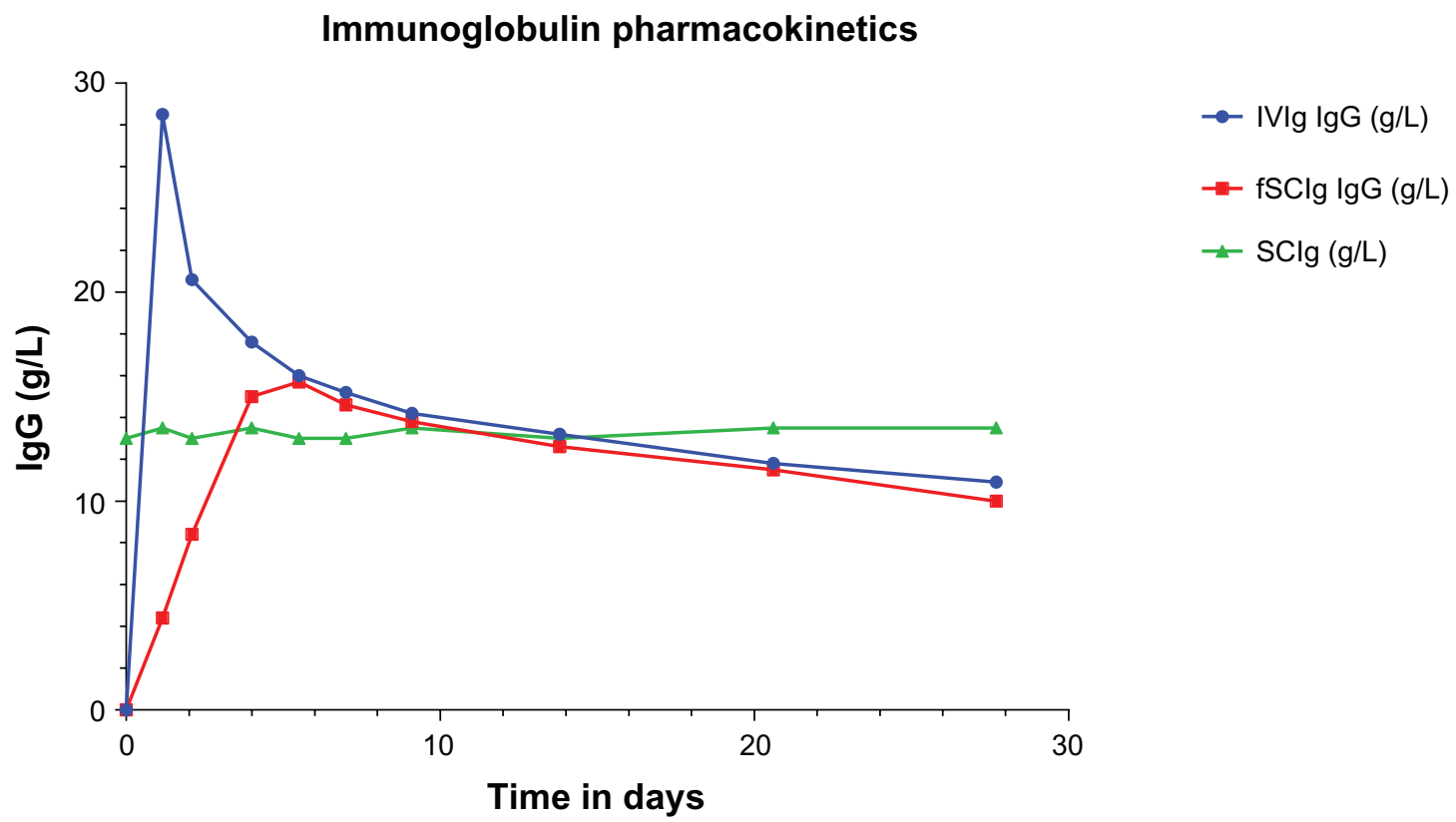

Figure 2 Immunoglobulin (Ig) pharmacokinetics for intravenous (IVIg), subcutaneous (SClg), and facilitated $\mathrm{SClg}$ (fSClg) administration. The graph shows an illustrative representation (not patient data) of the differences in the levels of IgG in the blood following IVIg in blue and fSClg infusion in red, both given as a first infusion, compared with conventional SClg in green, which is shown at a steady state over a 28-day time period. This shows the differences in the pharmacokinetics with the three methods of delivery, illustrating the loss of the peak level achieved with IVIg when fSClg is used, followed by (from around day I2) the very similar gradual decline in lgG levels over time. $\mathrm{SClg}$ is not represented from initiation of treatment, as this would take 3-6 months to reach a steady state unless an SClg-loading regimen was employed. 


\section{Hyaluronidase facilitated SCIg}

The recent prospective open-label study of the use of rHuPH20 facilitated $10 \%$ SCIg in 83 patients with primary antibody deficiency demonstrates the potential of this method of administration. ${ }^{35}$ Patients were first treated for 3 months with $10 \%$ IVIg, and following this received the same $10 \%$ preparation SC with hyaluronidase (IGHy) for 14-18 months.

The rHuPH20 was given first at a dose of $75 \mathrm{U} / \mathrm{g}$, followed by the subsequent $10 \%$ Ig infusion. The dose of Ig given was calculated to be $108 \%$ of the previous weekly IVIg dose, given a bioavailability of $92 \%$. The dose was then increased from weekly until the prestudy IVIg interval of 3 or 4 weeks was attained. This was then maintained for approximately 1 year, with the primary end point being the rate of serious bacterial infections. Patients were allowed to self-administer at home at infusion rates of $160 \mathrm{~mL} /$ hour for those weighing less than $40 \mathrm{~kg}$ and $300 \mathrm{~mL} /$ hour for those $>40 \mathrm{~kg}$. No limit was placed on the maximum volume administered per site, with a mean volume per site of $292.2 \mathrm{~mL}$ and maximum of $716 \mathrm{~mL}$. Remarkably, the infusion rates were higher than for equivalent IVIg infusions $(300 \mathrm{~mL} /$ hour versus $246 \mathrm{~mL} /$ hour). Of 69 patients who completed the treatmentsatisfaction questionnaire, $83 \%$ said they would prefer to continue fSCIg rather than IVIg or SCIg, with the main reasons cited being overall convenience, ability to fit treatment into their schedules, and frequency of administration.

Pharmacokinetic studies demonstrated a bioavailability of $93.3 \%$, a $20 \%$ increase over SCIg, and trough levels equivalent to IVIg. Whilst the peak-to-trough serum IgGconcentration differences $(4.8-11.5 \mathrm{~g} / \mathrm{L})$ were greater than for SCIg administration, they were significantly less than seen for IVIg. Trough levels in patients $>12$ years of age were $10.7 \mathrm{~g} / \mathrm{L}$ for IGHy and $10.4 \mathrm{~g} / \mathrm{L}$ for IVIg. The primary end point for the study was met with two serious bacterial infections of bacterial pneumonia during the 1-year efficacy period. The most common side effects were local discomfort, erythema, and swelling, and six subjects withdrew due to mild-to-moderate adverse reactions. Severe local reactions occurred in three of 1,129 IGHy infusions. The rate of systemic adverse events for IGHy (8.3\%) was less than one-third of that seen for IVIg (25\%) in the study. Thirteen patients developed anti-hyaluronidase antibodies on enzyme-linked immunosorbent assay testing, none of which were found to be neutralizing antibodies, and none appeared to relate to local or systemic adverse events.

Prior to the rHuPH20, study we reported the case of a patient who was trained to self-administer fSCIg at home using ovine hyaluronidase at $50 \mathrm{U} / \mathrm{g}$, as rhuPH20 was not available at the time. ${ }^{36}$ The reason for administering the fSCIg was that it had not been possible to attain adequate trough-IgG levels, even using 16 SCIg infusions per month. The 16\% SCIg preparation (Subcuvia; Baxter, Deerfield, IL, USA) administered with hyaluronidase allowed the patient to administer $130 \mathrm{~mL} / \mathrm{site}$ to two sites fortnightly, with improved trough levels. The patient has continued to use the same regimen for over 3.5 years using the same sites (Figure 3). The opportunity was taken to reassess the skin where the infusions had been given regularly. At the site of fSCIg infusions (thighs), fSCIg was administered to one side and SCIg to the other. The skin on the SCIg-alone thigh resulted in a typical raised and blanched area with a maximal volume of $30 \mathrm{~mL}$, while on the fSCIg side the infusion was completed as normal with the full $130 \mathrm{~mL}$. This suggested that there did not appear to be a clinically apparent change
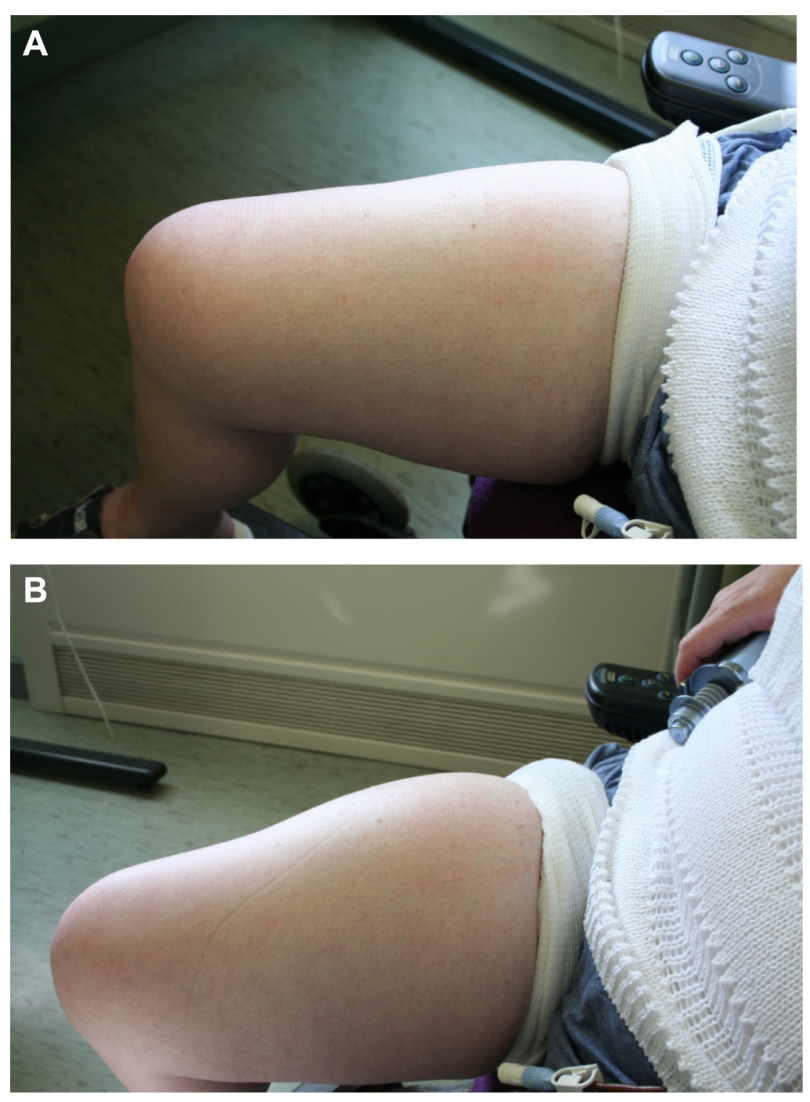

Figure 3 Skin pre- (A) and post- (B) hyaluronidase-facilitated subcutaneous immunoglobulin infusion ( $\mathrm{fSClg}$ ) after $3 \mathrm{I} / 2$ years of fortnightly infusions. Images of the thigh taken before and after the infusion of $130 \mathrm{~mL}$ of $16 \%$ Subcuvia (Baxter, Deerfield, IL, USA) at $100 \mathrm{~mL} /$ hour. $^{36}$ These show a diffuse swelling over a larger area than conventional $\mathrm{SClg}$ with an absence of blanching and erythema, as the fluid is more widely distributed in the SC space. The initial SC injection of ovine hyaluronidase at a dose of $50 \mathrm{U} / \mathrm{g}$ of $\mathrm{lgG}$ was immediately followed by the $\mathrm{lg}$ infusion. Reproduced from Journal of Clinical Pathology, Knight E, Carne E, Novak B, et al., 63(9), 846-847, 2010 with permission from BMJ Publishing Group Ltd. 
in the impedance to fluid flow in the skin of the thigh after 3.5 years of fortnightly infusions at that site.

\section{Patient profiles}

FSCIg may offer advantages to recipients firstly for clinical reasons, and secondly for reasons of patient choice and convenience. In the first category are those patients in whom it is difficult to achieve appropriate IgG-trough levels despite increased SCIg doses with maximum tolerated volumes at four or more sites per week. A similar situation can occur in a small proportion of IVIg-treated patients in whom troughs remain unsatisfactory despite high doses and a fortnightly dosing interval. The reasons for this are not always clear, there being wide variation between recipients in troughIgG levels using the same $\mathrm{g} / \mathrm{kg} /$ month dose despite little evidence of pulmonary, gastrointestinal, or renal IgG loss. Patients who may require higher IgG-trough levels include those with end-organ damage (bronchiectasis), very low IgA levels, and X-linked agammaglobulinemia patients. ${ }^{39,40}$ In addition, patients receiving IVIg who continue to have adverse effects despite having tried several IV products or who have poor venous access and who require higher doses may be considered for fSCIg.

In the second category are patients who are currently on SCIg and who wish to decrease the number of injections and infusion frequency, such as heavy adults. For example where a dose of $0.6 \mathrm{~g} / \mathrm{kg} / \mathrm{month}$ is being delivered, this is not attainable (even using a $20 \%$ product) with two sites per week at $35 \mathrm{~mL} / \mathrm{site}$ in patients over $90 \mathrm{~kg}$ in weight. Such patients will require injections at three to four SCIg sites weekly, and may thus choose fSCIg in order to reduce the number of injections from 12-16 to 1-2/month. Shorter infusion times enabled by fSCIg may also enhance their convenience and facilitate their timing and location (during the working day, evening or weekend, at hospital or home).

Patients who require IVIg for immunomodulation at doses of $1-2 \mathrm{~g} / \mathrm{kg} / \mathrm{month}$ can be trained for home therapy with SCIg, but the number of needles and infusions may be unacceptably high using either $16 \%$ or $20 \%$ SCIg products. Further studies in this area should inform whether the SC route has the potential to induce remission of disease as well as maintaining remission. Immunomodulation for inflammatory or autoimmune disease would currently be an off-license use of fSCIg.

\section{Discussion}

Ig-replacement therapy for PID patients is no longer a straight choice between either IVIg or SCIg. The options for physicians and patients now comprise IVIg, SCIg, fSCIg, and rapid push. A range of products are available for IVIg, SCIg, and rapid push, and the therapy chosen should be individually tailored for the patient. The improved choice will undoubtedly benefit patients, and training center staff with relevant experience should increasingly share their expertise with others to make these choices widely available.

These advances in Ig delivery are occurring in the context of changing views about what the most appropriate levels of replacement in PID should be, with a general move towards higher trough IgG levels where this is supported by a scientific evidence base and clinical improvements in patients. It is also increasingly important to consider that the optimal pharmacokinetics for Ig as an immunomodulator may be significantly different than its pharmacokinetics as replacement therapy. ${ }^{41}$

With the introduction of a new treatment such as fSCIg using rHuPH20, monitoring of long-term safety will be essential. While there is a long history of short-term use of hyaluronidase in humans, information on longer-term repeated administration to large numbers of patients is lacking. Monitoring of local effects on skin, potential development of antibodies (in particular, blocking antibodies to rHuPH20), effects on fertility, and possible immunological effects of the hyaluronidase fragments are some aspects that will require ongoing review. Thus far, there have encouragingly not been reports of problems in these areas with rHuPH20, with the exception of the development of nonblocking antibodies in 13 of 83 recipients. ${ }^{35}$

In conclusion, $\mathrm{rHuPH} 20 \mathrm{fSCIg}$ is an exciting development that offers more choice for patients and physicians. Its use in PID is likely to be influenced by the extra cost of rHuPH20 over and above the price for the Ig. A relevant cost-benefit analysis of savings from reduced need to attend for hospital infusions balanced against higher treatment costs should be helpful. Longer-term safety data will also be very valuable to inform treatment decisions. In the future, its use in an immunomodulatory setting needs to be explored, and also whether there are any advantages in using the higher concentrations of Ig that are already available subcutaneously.

\section{Acknowledgments}

$\mathrm{SJ}$ is supported by a NISCHR fellowship. Figure 1 was drawn by Pippa Jolles.

\section{Disclosure}

Support including consulting, speaker, travel, advisory board and research support from CSL Behring, Baxter, BPL, Biotest 
and Octapharma. The author reports no other conflicts of interest in this work.

\section{References}

1. Bruton OC. Agammaglobulinemia. Pediatrics. 1952;9(6):722-728.

2. Long AA, Denburg JA, Dent PB. Hypogammaglobulinemia: therapeutic rationale. CMAJ. 1987;137(9):793-797.

3. [No authors listed]. Hypogammaglobulinaemia in the United Kingdom. Summary report of a Medical Research Council working-party. Lancet. 1969;1(7587):163-168.

4. Roifman CM, Levison H, Gelfand EW. High-dose versus low-dose intravenous immunoglobulin in hypogammaglobulinaemia and chronic lung disease. Lancet. 1987;1(8541):1075-1077.

5. Gardulf A, Bjorvell H, Gustafson R, Hammarstrom L, Smith CI. Safety of rapid subcutaneous gammaglobulin infusions in patients with primary antibody deficiency. Immunodeficiency. 1993;4(1-4):81-84.

6. Gardulf A, Nicolay U. Replacement IgG therapy and self-therapy at home improve the health-related quality of life in patients with primary antibody deficiencies. Curr Opin Allergy Clin Immunol. 2006;6(6): 434-442.

7. Jolles S, Bernatowska E, de Gracia J, et al. Efficacy and safety of Hizentra ${ }^{\circledR}$ in patients with primary immunodeficiency after a doseequivalent switch from intravenous or subcutaneous replacement therapy. Clin Immunol. 2011;141(1):90-102.

8. Shapiro RS. Subcutaneous immunoglobulin: rapid push vs infusion pump in pediatrics. Pediatr Allergy Immunol. 2013;24(1):49-53.

9. Kim J, Hayton WL, Robinson JM, Anderson CL. Kinetics of FcRnmediated recycling of IgG and albumin in human: pathophysiology and therapeutic implications using a simplified mechanism-based model. Clin Immunol. 2007;122(2):146-155.

10. Orange JS, Belohradsky BH, Berger M, et al. Evaluation of correlation between dose and clinical outcomes in subcutaneous immunoglobulin replacement therapy. Clin Exp Immunol. 2012;169(2):172-181.

11. Orange JS, Grossman WJ, Navickis RJ, Wilkes MM. Impact of trough IgG on pneumonia incidence in primary immunodeficiency: a metaanalysis of clinical studies. Clin Immunol. 2010;137(1):21-30.

12. Berger M, Jolles S, Orange JS, Sleasman JW. Bioavailability of IgG administered by the subcutaneous route. J Clin Immunol. 2013;33(5): 984-990.

13. Bonagura VR, Marchlewski R, Cox A, Rosenthal DW. Biologic IgG level in primary immunodeficiency disease: the $\mathrm{IgG}$ level that protects against recurrent infection. J Allergy Clin Immunol. 2008;122(1):210-212.

14. Chaik E, Duthie ES. A mucolytic enzyme in testes extracts. Nature. 1939;144(3658):977-978.

15. Meyer K. The action of hyaluronidases on hyaluronic acid. Ann NY Acad Sci. 1950;52(7):1021-1023.

16. Frost GI. Recombinant human hyaluronidase (rHuPH20): an enabling platform for subcutaneous drug and fluid administration. Expert Opin Drug Deliv. 2007;4(4):427-440.

17. Csoka AB, Frost GI, Stern R. The six hyaluronidase-like genes in the human and mouse genomes. Matrix Biol. 2001;20(8):499-508.

18. Imundo L, Leduc CA, Guha S, et al. A complete deficiency of hyaluronoglucosaminidase 1 (HYAL1) presenting as familial juvenile idiopathic arthritis. J Inherit Metab Dis. 2011;34(5):1013-1022.

19. Olsson M, Meadows JR, Truve K, et al. A novel unstable duplication upstream of HAS2 predisposes to a breed-defining skin phenotype and a periodic fever syndrome in Chinese shar-pei dogs. PLoS Genet. 2011;7(3):e1001332.

20. Eberlein M, Scheibner KA, Black KE, et al. Anti-oxidant inhibition of hyaluronan fragment-induced inflammatory gene expression. J Inflamm (Lond). 2008;5:20.

21. Hascall VC, Majors AK, De La Motte CA, et al. Intracellular hyaluronan: a new frontier for inflammation? Biochim Biophys Acta. 2004;1673(1-2):3-12.
22. Pure E, Assoian RK. Rheostatic signaling by CD44 and hyaluronan. Cell Signal. 2009;21(5):651-655.

23. Gmachl M, Kreil G. Bee venom hyaluronidase is homologous to a membrane protein of mammalian sperm. Proc Natl Acad Sci U S A. 1993;90(8):3569-3573.

24. Gmachl M, Sagan S, Ketter S, Kreil G. The human sperm protein PH-20 has hyaluronidase activity. FEBS Lett. 1993;336(3):545-548.

25. Lathrop WF, Carmichael EP, Myles DG, Primakoff P. cDNA cloning reveals the molecular structure of a sperm surface protein, PH-20, involved in sperm-egg adhesion and the wide distribution of its gene among mammals. J Cell Biol. 1990;111(6 Pt 2):2939-2949.

26. Mace SE, Harb G, Friend K, Turpin R, Armstrong EP, Lebel F. Cost-effectiveness of recombinant human hyaluronidase-facilitated subcutaneous versus intravenous rehydration in children with mild to moderate dehydration. Am J Emerg Med. 2013;31(6):928-934.

27. Spandorfer PR, Mace SE, Okada PJ, et al. A randomized clinical trial of recombinant human hyaluronidase-facilitated subcutaneous versus intravenous rehydration in mild to moderately dehydrated children in the emergency department. Clin Ther. 2012;34(11):2232-2245.

28. Vaughn DE, Muchmore DB. Use of recombinant human hyaluronidase to accelerate rapid insulin analogue absorption: experience with subcutaneous injection and continuous infusion. Endocr Pract. 2011;17(6): 914-921.

29. Harb G, Lebel F, Battikha J, Thackara JW. Safety and pharmacokinetics of subcutaneous ceftriaxone administered with or without recombinant human hyaluronidase ( $\mathrm{rHuPH} 20)$ versus intravenous ceftriaxone administration in adult volunteers. Curr Med Res Opin. 2010;26(2): 279-288.

30. Supersaxo A, Hein WR, Steffen H. Effect of molecular weight on the lymphatic absorption of water-soluble compounds following subcutaneous administration. Pharm Res. 1990;7(2):167-169.

31. Laurent TC, Fraser JR. Hyaluronan. FASEB J. 1992;6(7):2397-2404.

32. Hechter O. Reconstitution of the dermal barrier to fluid diffusion following administration of hyaluronidase. Proc Soc Exp Biol Med. 1948;67(3):343

33. Matarasso SL, Carruthers JD, Jewell ML. Consensus recommendations for soft-tissue augmentation with nonanimal stabilized hyaluronic acid (Restylane). Plast Reconstr Surg. 2006;117(Suppl 3):3S-34S; discussion 35S-43S.

34. Jolles S, Sleasman JW. Subcutaneous immunoglobulin replacement therapy with Hizentra, the first $20 \%$ SCIG preparation: a practical approach. Adv Ther. 2011;28(7):521-533.

35. Wasserman RL, Melamed I, Stein MR, et al. Recombinant human hyaluronidase-facilitated subcutaneous infusion of human immunoglobulins for primary immunodeficiency. $J$ Allergy Clin Immunol. 2012;130(4):951-957. e11.

36. Knight E, Carne E, Novak B, et al. Self-administered hyaluronidasefacilitated subcutaneous immunoglobulin home therapy in a patient with primary immunodeficiency. J Clin Pathol. 2010;63(9):846-847.

37. Porter CJ, Charman SA. Lymphatic transport of proteins after subcutaneous administration. J Pharm Sci. 2000;89(3):297-310.

38. Smith GN, Griffiths B, Mollison D, Mollison PL. Uptake of IgG after intramuscular and subcutaneous injection. Lancet. 1972;1(7762): $1208-1212$.

39. Quinti I, Soresina A, Guerra A, et al. Effectiveness of immunoglobulin replacement therapy on clinical outcome in patients with primary antibody deficiencies: results from a multicenter prospective cohort study. J Clin Immunol. 2011;31(3):315-322.

40. Lucas M, Lee M, Lortan J, Lopez-Granados E, Misbah S, Chapel H. Infection outcomes in patients with common variable immunodeficiency disorders: relationship to immunoglobulin therapy over 22 years. J Allergy Clin Immunol. 2010;125(6):1354-1360. e4.

41. Kaveri SV, Maddur MS, Hegde P, Lacroix-Desmazes S, Bayry J. Intravenous immunoglobulins in immunodeficiencies: more than mere replacement therapy. Clin Exp Immunol. 2011;164 Suppl 2:2-5. 
ImmunoTargets and Therapy

\section{Publish your work in this journal}

ImmunoTargets and Therapy is an international, peer-reviewed open access journal focusing on the immunological basis of diseases, potential targets for immune

based therapy and treatment protocols employed to improve patient management

Basic immunology and physiology of the immune system in health, and disease will be also covered. In addition, the journal will focus on the impact of managesuch as quality of life, adherence and satisfaction. The manuscript management system is completely online and includes a very quick and fair peer-review system, which is all easy to use. Visit http://www.dovepress.com/testimonials.php to read real quotes from published authors.

Submit your manuscript here: http://www.dovepress.com/immunotargets-and-therapy-journal 